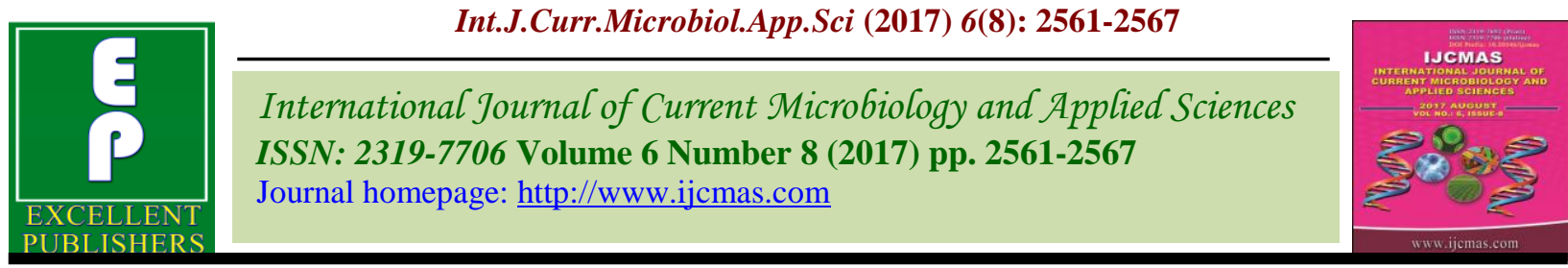

Original Research Article https://doi.org/10.20546/ijcmas.2017.608.303

\title{
Bacteriological Profile of Recurrent Upper Respiratory Tract Infection in Children Attending a Tertiary Care Hospital
}

\author{
Arpita Paul Dutta ${ }^{1}$, Sayantani Endow Dutta ${ }^{*}$, Rahul Mazumdar ${ }^{2}$, \\ Mridula Chatterjee ${ }^{2}$ and Arunabha Sarkar ${ }^{1}$
}
${ }^{1}$ Department of Microbiology, North Bengal Medical College, Darjeeling, West Bengal, India
${ }^{2}$ Department of Paediatrics, North Bengal Medical College, Darjeeling, West Bengal, India
*Corresponding author

\section{A B S T R A C T}

Keywords

Respiratory tract

infection,

Paediatric, Throat

swab, Bacterial

agents,

Antimicrobial

susceptibility.

Article Info

Accepted:

21 June 2017

Available Online:

10 August 2017
Paediatric respiratory tract infections are among the most common reasons for preschool and school absences and visits to physicians. The disease mainly involves upper respiratory tract and is associated with fever cough sore throat and running nose. Children with recurrent respiratory tract infections (RRTI), which are defined as more than or equal to 6 serious diseases a year, are a difficult diagnostic challenge. The study was conducted with an aim to identify the causative bacterial agents of recurrent upper respiratory tract infection with their antimicrobial susceptibility pattern in children attending the paediatric outpatient department of North Bengal Medical College from January 2016 to December 2016. Throat swab samples from 200 suspected cases of RRTI were collected and plated in Blood agar, MacConkey agar and chocolate agar. The organism isolated on medium were identified by their cultural, morphological and biochemical characteristics. Bacterial infection was isolated in 101 patients. The bacterial agents isolated were Staphylococcus aureus, Streptococcus pyogenes, Streptococcus pneumonia, Klebsiella pneumoniae and Moraxella catarrhalis. Antimicrobial susceptibility pattern revealed that the overall sensitivity of all the isolates were maximum towards cefuroxime and levofloxacin. The study indicates the need of continuous surveillance on antimicrobial susceptibility of upper respiratory tract infection for detection of emerging trends and use of appropriate therapeutic interventions.

\section{Introduction}

Paediatric respiratory tract infections are one of the most common reasons for physician visits and hospitalisation and are associated with significant morbidity and mortality (Jacobs et al., 2009). It has been widely acclaimed that the respiratory tract is the most frequent site of infection as it comes into direct contact with the physical environment and is exposed to airborne microorganisms such as viruses, bacteria, fungi and parasites (El Mahamood et al., 2010).
Every year acute respiratory tract infection (ARI) in young children is responsible for an estimated 4.1 million deaths worldwide. It is estimated that Bangladesh, India, Indonesia and Nepal together account for $40 \%$ of the global ARI, which are bacterial in origin (Shrestha et al., 2006) There is a widespread agreement that viruses are the principal initiators of RTIs (Ndip et al., 2001). In case of upper respiratory tract infections (URTI) only $25 \%$ of cases are due to bacteria, mostly 
are viral and in case of lower respiratory tract infections (LRTI) 50-60\% cases are due to bacteria (Michael et al., 2008; Kabra et al., 2001).The most common bacteria implicated in causing RTI are Staphylococcus aureus, Streptococcus pneumoniae, Streptococcus pyogenes, Klebsiella pneumoniae, Acinetobacter sp. (Riley and Riley., 2003; Rudan et al., 2008). Respiratory tract infections (RTI), mainly involving the upper airways, are common in children and their recurrence constitutes a demanding challenge for the paediatricians (Jesenak et al., 2011). Recurrent respiratory tract infections (RRTI) are defined as acute respiratory infections occurring 8 episodes per year if age $<3$ years and or 6 episodes per year if age $>$ or $=3$ years (Principi et al., 2003). Some children experience considerable morbidity as a result of RRTIs and receive repeated courses of antibacterials that are not effective against viral infectious agents and can increase bacterial resistance (El Mahamood et al., 2010).

Respiratory diseases have overtaken diarrhoea as the most frequent cause of death among children in developing countries, with $S$. pneumoniae among others being one of the main pathogenic species (Herruzo et al., 2002). Cases of acute RTIs are known to respond to antibiotics. However, the overuse and misuse of antibiotics for upper RTIs in children is widespread and fuelled by public attitudes and expectations heralding the emergence of resistance (Parimi et al., 2004). The ever-increasing tendency to purchase drugs over-the-counter in our environment heralds the emergence of resistant strains of pathogens posing a great problem in the treatment and control of such pathogens (Ndip et al., 2001).

The study is an effort to find out the potential pathogen (mainly bacteria) and magnitude of community acquired recurrent respiratory tract infections in pediatric age group at a tertiary care hospital and to assess the pattern of RRTI isolates by antibiogram so that guideline for the empirical treatment of such infections can be formulated where facilities for culture do not exist.

\section{Materials and Methods}

\section{Study setting}

The study was conducted in the Department of Microbiology, North Bengal Medical College, West Bengal, India. Pediatric patients of 5 to 12 years of age attending Pediatric out-patient department of North Bengal Medical College and Hospital with symptoms and signs of recurrent respiratory tract infection were included in the study.

The study was carried out for a period of one year from January 2016 to December 2016. Following inclusion and exclusion criteria were applied for selecting the cases:

\section{Inclusion criteria}

Children belonging to the age group 5 to 12 years with history of recurrent symptoms of rhinorrhea, sneezing, sore throat, fever, cough, nasal congestion, hoarseness

OPD pediatric patients

Had not taken antibiotics for the preceding one week

\section{Exclusion criteria}

Indoor patients

Critically ill patients

Children with anatomical defects of upper respiratory tract mainly cleft lip and cleft palate. 


\section{Sample collection and processing}

A total of 200 children were included as per the inclusion and exclusion criteria. 2 throat swab samples were collected from each patient and processed in the department of microbiology. Direct smear was prepared from one of the specimen for gram staining. The other specimen was inoculated in blood agar, chocolate agar, and Mac Conkey agar. The inoculated plates were incubated at $37^{\circ} \mathrm{C}$ for 24-48 $\mathrm{h}$ aerobically, except for chocolate agar, which were incubated for $24-48 \mathrm{~h}$ at $37^{\circ} \mathrm{C}$ in an atmosphere of $5-10 \% \mathrm{CO}_{2}$. After incubation, macroscopic and microscopic examinations of colonies on plates were carried out, and suspected colonies were subcultured on appropriate solid culture media for obtaining pure culture. Colonies were identified by specific tests where necessary such as, optochin sensitivity and bile solubility tests for Streptococcus pneumoniae, bacitracin sensitivity test for Streptococcus pyogenes and appropriate biochemical tests including TSI (Triple Sugar Iron), Citrate, MIU (Motility Indole Urea) media, for Enterobacteriaceae like Klebsiella pneumoniae. Pure cultures of Moraxella yielding oxidase, catalase test, showing no growth on nutrient agar at room temperature, failure to ferment glucose, lactose, mannitol and sucrose were considered significant. Profiling of antimicrobial susceptibility/resistance was performed by Kirby Bauer disc diffusion method (Kirby et al., 1966) and the bacterial strains were identified as either sensitive or resistant to an antibiotic based on the diameter of inhibition zone interpretative chart, published in Clinical and Laboratory Standard Institute (CLSI) guidelines 2016.

\section{Results and Discussion}

Of the total 200 throat swab specimen processed in the department of microbiology,
101 (50.5\%) were culture positive for potential pathogens. Rest 99 samples were commensals and were not included in the study. The bacteria isolated were Staphylococcus aureus (41.5\%), Streptococcus pyogenes (19.8\%), Streptococcus pneumoniae (15.8\%), Klebsiella pneumoniae (12.8\%), Moraxella catarhhalis (9.9\%) (Fig. 1). Of the 101 isolates identified, $63.3 \%$ were from males compared to $36.6 \%$ from females (Table 1). Culture positivity was seen maximum in the age group 5-6 years (34\%) (Table 2). The susceptibility pattern of isolates to various antibiotics is shown in table 3. Cefuroxime and levofloxacin exhibited good susceptibility against all the isolates. $S$. aureus and $S$. pneumoniae showed $100 \%$ sensitivity to linezolid.

In this study the prevalence of bacteria among upper respiratory tract infection was found to be $50.5 \%$. Staphylococcus aureus was the commonest pathogen (41.5\%) followed by Streptococcus pyogenes (19.8\%), Streptococcus pneumoniae (15.8\%), Klebsiella pneumoniae (12.8\%) and Moraxella catarrhalis (9.9\%). A study by Kousalya et al., (2010) and Josphat et al., (2017) also reported Staphylococcus aureus as the predominant isolate from upper respiratory tract infection in children with isolation rate of $45.61 \%$ and $44.3 \%$ respectively. In contrast to the above, studies done by Shrestha et al., (2006) and Loganathan et al., (2006) reported Streptococcus pyogenes as the predominant isolate in children. Climatic and geographic variation could be the possible reasons for the difference in distribution of bacteria.

Most of the organisms isolated were Gram positive organisms. The respiratory tract infection is caused by air-borne pathogens that survive under dry conditions for long period of time. According to Madigan gram 
positive bacteria are more resistant to drying than gram-negative bacteria because of their thicker, more rigid cell wall; and also the human pathogens (Staphylococcus, Streptococcus) survive under dry conditions fairly well and remain alive in dust for long time (Madigan et al., 1996).

Pathogens were isolated mostly from children of 5-6 years of age and from males. However there was no significant difference $(p>0.05)$ in the prevalence of pathogens related to age and sex suggesting that upper respiratory tract infection is not age or sex related. As majority of the children were from low socioeconomic background, overcrowding, poor hygiene, low immune status, malnutrition could be the possible factors that enhanced the spread of pathogens. Imbalance of the oral microbiota as a result of broad-spectrum antibiotics which eliminate the competing bacteria and disrupt the normally balanced ecology of oral micro-organisms or medication with corticosteroids may also predispose patients to these infections (Josphat et al., 2017).

Since antibiotic resistance, is an interdisciplinary global concern, is emerging in an alarmingly increasing manner, the study also aimed to investigate antibiotic resistance patterns for the isolated bacteria. Table 3 shows that Staphylococcus aureus is the predominating isolate showing sensitivity of $90.4 \%$ to levofloxacin and cefuroxime and $78.5 \%$ to gentamycin. However a disappointing antibiotic susceptibility pattern of $S$. aureus was observed for other antibiotics including penicillin, amoxyclav, cotrimoxazole and azithromycin with a susceptibility rate of $21.4 \%, 26.1 \%, 16.6 \%$ and $59.5 \%$ respectively. The major elective force favouring the emergence of antibiotic resistance is their extensive use. The low rate of susceptibility to penicillin $(21.4 \%)$ and cotrimoxazole $(16.6 \%)$, which are commonly bought over-the-counter in drug stores, contrasts with the marked levels of susceptibilities of the isolates to cefuroxime and levofloxacin which are less-frequently used, thus suggesting a relationship between antibiotic use and the level of drug resistance encountered in this study as previously suggested in another study. It was observed that Streptococcus pyogenes was highly susceptible to cefuroxime (90\%), levofloxacin (90\%), gentamycin (80\%) followed by amoxyclav $(75 \%)$ and penicillin $(70 \%)$.

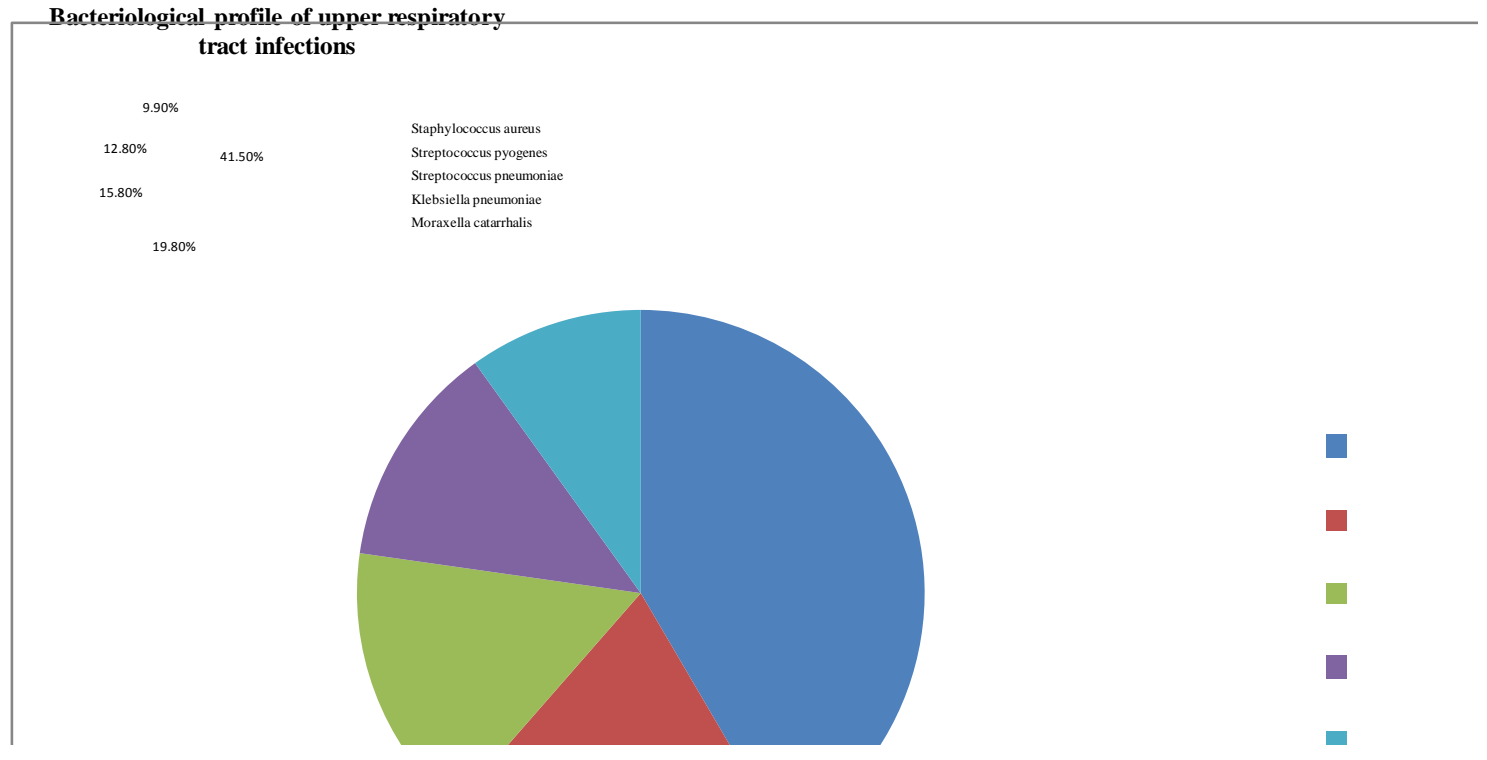


Table.1 Gender wise distribution of bacterial pathogens

\begin{tabular}{|l|l|l|l|l|l|l|}
\hline Gender & $\begin{array}{l}\text { S. aureus } \\
\text { No }(\%)\end{array}$ & $\begin{array}{l}\text { S. pyogenes } \\
\text { No }(\%)\end{array}$ & $\begin{array}{l}\text { S. pneumoniae } \\
\text { No }(\%)\end{array}$ & $\begin{array}{l}\text { K. pneumoniae } \\
\text { No }(\%)\end{array}$ & $\begin{array}{l}\text { M. catarrhalis } \\
\text { No }(\%)\end{array}$ & Total \\
\hline Male & $28(43.75)$ & $15(23.43)$ & $8(12.5)$ & $6(9.37)$ & $7(10.9)$ & 64 \\
\hline Female & $14(37.83)$ & $5(13.51)$ & $8(21.62)$ & $7(18.9)$ & $3(8.10)$ & 37 \\
\hline Total & $42(41.5)$ & $20(19.8)$ & $16(15.8)$ & $13(12.8)$ & $10(9.9)$ & 101 \\
\hline
\end{tabular}

Table.2 Age wise distribution of culture positive cases

\begin{tabular}{|l|l|l|l|}
\hline Age group (in yrs) & No. of males & No. of females & Total number $(\%)$ \\
\hline $5-6$ & 25 & 9 & $34(33.66 \%)$ \\
\hline $7-8$ & 17 & 5 & $22(21.78 \%)$ \\
\hline $9-10$ & 12 & 13 & $25(24.75 \%)$ \\
\hline $11-12$ & 10 & 10 & $20(19.80 \%)$ \\
\hline Total & 64 & 37 & 101 \\
\hline
\end{tabular}

Table.3 Susceptibility (\%) of bacterial strains to antibiotics

\begin{tabular}{|l|l|l|l|l|l|l|l|l|l|l|}
\hline $\begin{array}{l}\text { Bacterial } \\
\text { strains }\end{array}$ & $\mathrm{N}$ & $\begin{array}{l}\mathrm{PnG} \\
(\%)\end{array}$ & $\begin{array}{l}\text { AG } \\
(\%)\end{array}$ & $\begin{array}{l}\text { COT } \\
(\%)\end{array}$ & $\begin{array}{l}\text { GM } \\
(\%)\end{array}$ & $\begin{array}{l}\text { LE } \\
(\%)\end{array}$ & $\begin{array}{l}\text { AZK } \\
(\%)\end{array}$ & $\begin{array}{l}\text { CFX } \\
(\%)\end{array}$ & $\begin{array}{l}\text { LZ } \\
(\% 0\end{array}$ & $\begin{array}{l}\text { IPM } \\
(\%)\end{array}$ \\
\hline S. aureus & 42 & 21.4 & 26.1 & 16.6 & 78.5 & 90.4 & 59.5 & 90.4 & 100 & - \\
\hline S. pneumoniae & 16 & 37.5 & 56.2 & 31.2 & 62.5 & 81.2 & 50.0 & 93.7 & 100 & - \\
\hline K. pneumoniae & 13 & 38.4 & 53.8 & 38.4 & 69.2 & 76.9 & - & 92.3 & - & 100 \\
\hline M. catarrhalis & 10 & 30.0 & 40.0 & 40.0 & 80.0 & 80.0 & 60.0 & 90.0 & - & - \\
\hline S. pyogenes & 20 & 70 & 75 & 50 & 80 & 90 & 60 & 90 & 100 & \\
\hline
\end{tabular}

$\mathrm{N}=$ total number of isolates

$\mathrm{PnG}=$ Penicillin, $\mathrm{AG}=$ Amoxyclav, $\mathrm{COT}=$ Cotrimoxazole, $\mathrm{GM}=$ Gentamycin, $\mathrm{LE}=$ Levofloxacin, $\mathrm{AZK}=$ Azithromycin, CFX=Cefuroxime, $\mathrm{LZ}=$ Linezolid

Gillespie states that penicillin has long been regarded as the treatment of choice in streptococcal tonsillitis and had a high in vitro activity against $S$. pyogenes infections but treatment failures of $S$. pyogenes have always been recognized (Markowitz et al., 1993). The isolates of Streptococcus pneumonia also showed higher sensitivity to cefuroxime (93.7\%). This finding was similar to study done by Bhuyan et al., (Dhaka) who also reported higher susceptibility to $3^{\text {rd }}$ generation cephalosporins. All the isolates of $S$. aureus and $S$. pneumoniae were susceptible to linezolid (100\%).

The susceptibility pattern reveals that cefuroxime and levofloxacin could be the treatment of choice in children with upper respiratory tract infection in our area as all the isolates including $K$. pneumoniae and $M$. catarrhalis showed higher susceptibility to these drugs. The use of penicillin, amoxicillin-clavulanic acid combination and cotrimoxazole as first choice drugs in upper respiratory tract infection should be discouraged as our data have shown increasing resistance of the aetiologic agents. Our study has shown the imperative of continuous surveillance of antimicrobial susceptibility for early detection of emerging resistance trends and adjustment and usage of appropriate therapeutic interventions. The possible role of fungi and viruses was not within the scope of this study. The increasing frequency of antibiotic resistance has been reported first in infections at sites where 
penetration of the antimicrobial agent is restricted and the level of therapeutic concentrations is consequently more difficult to be achieved. It could also hinder the eradication of infections in respiratory tract treated using standard antibiotic therapy regimens (Dagan et al., 2001). Accurate information on local epidemiology and antimicrobial resistance patterns of pathogens is essential to select a clinically effective antibiotic therapy for the infections (Bassetti et al., 2000).

In conclusion, the indiscriminate and unreasonable uses of antibiotics have contributed to the emergence of resistance, which may turn out to be a leading cause of morbidity and mortality in the developing countries. A tailored antibiotic treatment is in demand to tackle this major issue, but the dearth of information regarding the etiological agents and antibiotic sensitivity patterns have made it difficult. The information regarding antibiotic resistance patterns provided here in this study is expected to raise alertness among physicians, community people, as well as among policy makers. Keeping in mind the increasing prevalence of drug resistant strains, we need to review the drug susceptibility in our region, hence, prescribing the more sensitive drug at an earlier phase of infection and improving the outcome of our patients.

\section{Acknowledgement}

We would like to thank Principal of the institution for allowing us to carry on with the study.

\section{References}

Bassetti, D., Bassetti, M., Mantero, M. 2000. Strategies for antibiotic selection in empirical therapy. Clin. Microbiol. Infect. 6:98-100.

Bhuyan, G.S., Hossain, M.A., Sarker, S.K.,
Rahat, A., Islam, M.T., Haque, T.N, et $a l ., 2017$. Bacterial and viral pathogen spectra of acute respiratory infections in under-5 children in hospital settings in Dhaka city. PLoS ONE.12 (3):448-454.

Dagan, R., Klugman, K.P., Craig, W.A., Baquero, F.2001. Evidence to support the rationale that bacterial eradication in respiratory tract infection is an important aim of antimicrobial therapy. J. Antimicrob. Chemother. 47:129-140.

El-Mahmood, A.M., Isa, H., Mohammed, A., Tirmidhi, A.B. 2010. Antimicrobial susceptibility of some respiratory tract pathogens to commonly used antibiotics at the Specialist Hospital, Yola, and Adamawa State, Nigeria. J Clin Med Res. 2:135-42.

Herruzo, R., Chamorrol, L., García, M.E., González, M.C, et al., 2002. Prevalence and antimicrobial-resistance of $S$. pneumoniae and $S$. pyogenes in healthy children in the region of Madrid. Int $\mathbf{J}$ Pediatr Otorhinolaryngol. 65:117-23.

Jacobs, E., Dalhoff, A., Korfmann, G. 2009.Susceptibility patterns of bacterial isolates from hospitalised patients with respiratory tract infections. International Journal of Antimicrobial.Agents.33:5257.

Jesenak, M., Ciljakova, M., Rennerova Z., Babusikova, E., Banovcin, P.2011. Recurrent Respiratory Infections in Children-Definition, Diagnostic Approach, Treatment and Prevention, Bronchitis (Eds) Dr Ignacio MartanLoeches. In Tech, Slovakia. Pp: 308320.

Josphat, M., John, M., Anthony, K. 2017. Antimicrobial susceptibility pattern of bacteria associated with upper respiratory tract infections in Kitui, Kenya. Ethiop Med J. 55(2):121-127

Kabra, S.K., 2001. Respiratory System. In Ghai Essential Pediatrics (Eds) Gupta 
Piyush, Paul V.K. Meheta Publishers, New Delhi.Pp.344-359.

Kirby, J.C., Bauer, A.W., Sherris, W.M.M., Turck, M.1966.Antibiotic susceptibility testing by a standardised single disk method. Am. J. Clin. Pathol., 36: 493496.

Kousalya, K., Thirumurugu, S., Arumainayagam, D.C., Manavalan, R., Vasanatha, J., and Reddy, U.M. 2010. Antimicrobial Resistance of bacterial agents of the upper respiratory tract in South Indian Population. Journal of Advanced Pharmaceutical Technology and Research.1 (2):207-15.

Loganathan, A., Arumainathan, U. D., Raman, R. 2006. Comparative study of bacteriology in recurrent tonsillitis among children and adults. Singapore Med J.47 (4):271-5.

Madigan, M.T., Martinko, Parker, J. 1996. Respiratory tract infection in Brock's biology of Microorganisms. (Eds).Michael T, Martinko, John M. Prentice Hall, USA. Pp: 350-358.

Markowitz, M.1993.Treatment of Streptococcal pharyngo-tonsillitis. Journal of Pediatric.123: 679-85.

Michael, A., Rubin, G.R. A., Merly, S.2008. Pharyngitis, sinusitis otitis and other respiratory tract infections In Harrison's Principle of Internal Medicine (Eds) Kasper, Braunwals, Fauci, Hanser, Longo, Jameson. Mc Graw Hill, USA. Pp. 205-214.

Ndip, R.N., Titanji, V.P.K., Akenji, T.N., Mutanga, A.M., Mbacham, W.F., Ndip,
L.M.2001. Antibiogram of Klebsiella pneumoniae isolates from Buea, Cameroon. Cent Afri J Med. 47:173-6.

Ndip, R.N., Akoachere, T.K., Mokosso, D.K., Ndip, L.M., Anyangwe, I.A.N. 2002.Carriage of Vibrio species by shimps harvested from the coastal waters of South West Cameroon. East Afri. Med. J. 79:146-9.

Parimi, N., Pinto Pereira, L.M, Prabhakar, P.2004. Caregivers' practices, knowledge and beliefs of antibiotics in paediatric upper respiratory tract infections in Trinidad and Tobago: a cross-sectional study. BMC Fam Pract. 25:28.

Principi, N., Esposito, S., Cavagna, R., Bosis $\mathrm{S}$ et al., 2003. Recurrent respiratory tract infections in paediatric age, a population based survey of the therapeutic role of macrolides. Journal of Chemotherapy. 15(1):53-9.

Riley, C., Riley, S.2003. Influenza and pneumococcal disease in the community. Nurs. Standard, 18(4): 4551.

Rudan, I., Boschi-Pinto, C., Biloglav, Z., Mulholland, K., Campbell, H. 2008. Epidemiology and etiology of childhood pneumonia. Bull. World Health Org.86: 408-416.

Shrestha, A., Sherchand, J.B., Sharma, P.R., Bhatta, D.R. 2006.Bacteriological study of upper respiratory tract infection in pediatric patients. Journal of Institute of Medicine. 28(3):28-31.

\section{How to cite this article:}

Arpita Paul Dutta, Sayantani Endow Dutta, Rahul Mazumdar, Mridula Chatterjee and Arunabha Sarkar. 2017. Bacteriological Profile of Recurrent Upper Respiratory Tract Infection in Children Attending a Tertiary Care Hospital. Int.J.Curr.Microbiol.App.Sci. 6(8): 2561-2567. doi: https://doi.org/10.20546/ijcmas.2017.608.303 